ACCEPTED MANUSCRIPT • OPEN ACCESS

\title{
Coaxial electrospun biomimetic copolymer fibres for application in diffusion magnetic resonance imaging
}

To cite this article before publication: Fenglei Zhou et al 2021 Bioinspir. Biomim. in press https://doi.org/10.1088/1748-3190/abedcf

\section{Manuscript version: Accepted Manuscript}

Accepted Manuscript is "the version of the article accepted for publication including all changes made as a result of the peer review process, and which may also include the addition to the article by IOP Publishing of a header, an article ID, a cover sheet and/or an 'Accepted Manuscript' watermark, but excluding any other editing, typesetting or other changes made by IOP Publishing and/or its licensors"

This Accepted Manuscript is @ 2021 The Author(s). Published by IOP Publishing Ltd.

As the Version of Record of this article is going to be / has been published on a gold open access basis under a CC BY 3.0 licence, this Accepted Manuscript is available for reuse under a CC BY 3.0 licence immediately.

Everyone is permitted to use all or part of the original content in this article, provided that they adhere to all the terms of the licence https://creativecommons.org/licences/by/3.0

Although reasonable endeavours have been taken to obtain all necessary permissions from third parties to include their copyrighted content within this article, their full citation and copyright line may not be present in this Accepted Manuscript version. Before using any content from this article, please refer to the Version of Record on IOPscience once published for full citation and copyright details, as permissions may be required. All third party content is fully copyright protected and is not published on a gold open access basis under a CC BY licence, unless that is specifically stated in the figure caption in the Version of Record.

View the article online for updates and enhancements. 


\title{
Coaxial electrospun biomimetic copolymer fibres for application in diffusion magnetic resonance imaging
}

Feng-Lei Zhou ${ }^{1,2}$, Damien J McHugh ${ }^{3}$, Zhanxiong Li ${ }^{4}$, Julie E. Gough ${ }^{5}$, Gareth R. Williams², and Geoff J.M. Parker ${ }^{1,6}$

${ }^{1}$ Centre for Medical Image Computing, Department of Computer Science, University College London, London, WC1V 6LJ, UK

${ }^{2}$ School of Pharmacy, University College London, London WC1N 1AX, UK

${ }^{3}$ Quantitative Biomedical Imaging Laboratory, The University of Manchester, Manchester, UK

${ }^{4}$ College of Textile and Clothing Engineering, Soochow University, Suzhou, 215021, P.R. China

${ }^{5}$ Department of Materials and Henry Royce Institute, The University of Manchester, Manchester M13 9PL, United Kingdom

${ }^{6}$ Bioxydyn Limited, Manchester, UK

E-mail: fenglei.zhou@ucl.ac.uk and geoff.parker@ucl.ac.uk

KEYWORDS: coaxial electrospinning, copolymers, hollow microfibres, imaging phantoms, diffusion magnetic resonance imaging

\begin{abstract}
Objective. The use of diffusion magnetic resonance imaging (dMRI) opens the door to characterise brain microstructure because water diffusion is anisotropic in axonal fibres in brain white matter and is sensitive to tissue microstructural changes. As dMRI becomes more sophisticated and microstructurally informative, it has become increasingly important to use a reference object (usually called imaging phantom) for validation of dMRI. This study aims to develop axon-mimicking physical phantoms from biocopolymers and assess their feasibility to validate dMRI measurements. Approach. We employed a simple and one-step method-coaxial electrospinning-to prepare axon-mimicking hollow microfibres from polycaprolactone- $b$-polyethylene glycol (PCL- $b$-PEG) and poly(D, L-lactideco-glycolic) acid (PLGA), and used them as building elements to create axon-mimicking phantoms. Electrospinning was firstly conducted using two types of PCL- $b$-PEG and two types of PLGA with different molecular weights in various solvents with different polymer concentrations for determining their spinnability. The polymer/solvent-concentration combinations with good fibre spinnability were used as the shell material in the following co-electrospinning process in which the polyethylene oxide (PEO) polymer was used as the core material. Following microstructural characterisation of both electrospun and co-electrospun fibres using optical and electron microscopy, two prototype phantoms were constructed from co-electrospun anisotropic hollow microfibres after inserting them into waterfilled test tubes. Main results. Hollow microfibres that mimic the axon microstructure were successfully prepared from the appropriate core and shell material combinations. dMRI measurements of two phantoms on a 7 tesla $(\mathrm{T})$ pre-clinical scanner revealed that diffusivity and anisotropy measurements are in the range of brain white matter. Significance. This feasibility study showed that co-electrospun PCL-b-PEG and PLGA microfibres-based axon-mimicking phantoms could be used in the validation of dMRI methods which seek to characterise white matter microstructure.
\end{abstract}

\section{Introduction}

Soft tissues such as human brain white matter and cardiac muscle exhibit a preferred microstructural orientation, with axonal fibres of $0.16-9 \mu \mathrm{m}$ [1] and cardiac myocytes of 10-25 $\mu \mathrm{m}$ [2] in diameter. Diffusion magnetic resonance imaging (dMRI) has become a non-invasive tool to characterise such microstructure, due to the fact that water diffusion is anisotropic in these fibrous tissues and is sensitive to tissue microstructural changes [3]. Physical phantoms have been widely used for validation of dMRI 
methods applied to neurology, such as tractography and microstructure measurement [4]. Melt-spun hollow microfibres [5, 6] and 3D printed fibres [7] have shown potential for use in the construction of axon-mimicking MR phantoms. Despite the promise of these approaches, they suffer from a number of disadvantages. Melt-spun hollow polypropylene (PP) fibres have $\sim 12 \mu \mathrm{m}$ inner diameter and are mono-dispersed [5], whereas fused deposition modelling (FDM) 3D printed fibres have a thickness of $0.2 \mathrm{~mm}$ [7], neither of which provides a realistic mimic of axonal dimensions. The construction processes of both melt-spun microfibre-based phantoms and 3D printed phantoms involves multiple steps and require high temperature during processing. For instance, preparing PP fibre phantom involves melt spinning at 210 degrees Celsius(C) and then the manual assembly of tens of thousands of filaments into small chambers $\sim 10$ square millimetres in size [8]; the fibre packing density and orientation in the hollow PP fibre phantoms are manually controlled after melt-spinning [6];3D printed phantom construction involves 3D printing of an ink composed of polyvinyl alcohol (PVA)+rubber elastomer at high temperature of 230 degrees $C$ and PVA removal via sonic water rinsing [9]; the 3D printing process allows automation of the process of generating MRI phantoms with controllable fibre orientation [9]. In addition, the polymer used to generate melt-spun axon-mimicking fibres, namely polypropylene (PP), is highly hydrophobic, which has made water-filling process labour-intensive in PP-derived fibre phantoms [6]. Most recently, hydrophilic Nylon hollow microfibres with 0.8 to $5 \mu \mathrm{m}$ in diameter were prepared via bi-component melt-spinning for the construction of axon-mimicking phantoms $[10,11]$. These hollow microfibres allow water to enter the phantoms more easily than those PP microfibres but involve using highly sophisticated spinneret and a two-step procedure. Two high temperature involved melt spinning and FDM 3D printing techniques are not "green" processes.

Co-electrospun hollow polycaprolactone (PCL) fibres have been produced in the approximate range 1 to $13 \mu \mathrm{m}[12,13]$, providing a fibre diameter distribution which mimics in vivo microstructure more closely than other phantom materials developed to date. The formation of axon-mimicking hollow microfibres via co-electrospinning involves fabrication in a one-step process at room temperature [12, 14]. Fibre packing and orientation is mainly determined by the jet deposition process, which can be tuned in a process often called direct-jet co-electrospinning [15]. This can be achieved by optimizing the translation speed of an $x-y$ translating mechanical collector [16] or introducing a pair of auxiliary electrodes to the $x-y$ collector [17]. In addition, co-electrospun hollow hydrophobic fibre phantoms (e.g. PCL) can readily be made hydrophilic by adding a surfactant in the spinning solution in the coelectrospinning process [18]. Overall, co-electrospinning has several advantages over melt-spinning and $3 \mathrm{D}$ printing technologies in terms of available polymers, relative simplicity of one-step formation at room temperature and tuning of microstructural and chemical properties.

Polycaprolactone (PCL) and poly(D,L-lactide-co-glycolic) acid (PLGA, Fig. 1a) are FDA-approved biopolymers that are widely processed via electrospinning or electrospraying into fibres or particles for biomedical applications such as tissue engineering and drug delivery $[19,20]$. PCL is semicrystalline and hydrophobic polymer; PLGA is a copolymer of poly lactic acid (PLA) and poly glycolic acid (PGA). Glycolic acid is more hydrophilic than lactic acid, and therefore a higher ratio of glycolic acid-to-lactic acid increases the hydrophilicity of the polymer. Poly(ethylene glycol) (PEG) is a water soluble polymer and has also received approval from the FDA for application mainly in drug delivery [21]. PEG is often combined with several polymers, such as PCL- $b$-PEG (Fig. 1b), polylactide (PLA), poly(glycolic acid) (PGA) and their co-polyesters (PLGA) to increase their biocompatibility and to allow them to be used as drug carriers. For instance, to improve the hydrophilicity and regulate the biodegradation rate of PCL, random and block copolymers of PCL with PEG can be prepared. The PCL- $b$-PEG copolymer has been widely applied in the design of drug delivery systems [22-24]. Due to their ease of processing by electrospinning and tuneable hydrophilicity, these two co-polymers may have great potential in creating water-filled axon-mimicking phantoms for the validation of diffusion MRI. 
$\mathbf{a}$<smiles>CC(OC(=O)CO[TlH])C(=O)O</smiles>

b

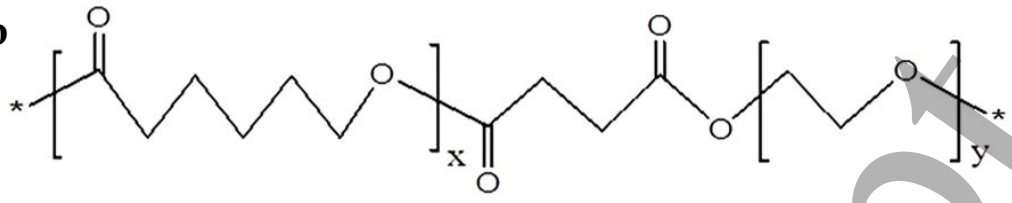

Figure 1. Chemical structures of (a) polylactic-co-glycolic acid (PLGA) ( $x$ is the number of lactic acid units and $\mathrm{y}$ is number of glycolic acid units) and (b) PCL- $b$-PEG ( $\mathrm{x}$ is the number of caprolactone units and $\mathrm{y}$ is number of ethylene glycol units).

Here we report for the first time the one-step formation of hollow microfibres from PCL- $b$-PEG and PLGA via co-electrospinning, as well as the feasibility of using these fibres to create axon-mimicking MRI phantoms. Electrospinning is firstly conducted using PCL- $b$-PEG and PLGA polymers. The solution properties (e.g. polymer molecular weight, solvent and solution concentration) and process parameters (e.g. applied voltage, working distance and flow rate) are optimized to produce smooth fibres from these two polymers. The polymer solutions that show good fibre spinnability are used as the shell material in the subsequent co-electrospinning process in which the highly spinnable polyethylene oxide (PEO) polymer is used as the core material. Optical and electron microscopy is used to determine the microstructure of both electrospun and co-electrospun fibres. Hollow microfibres that mimic brain axon microstructure are successfully prepared from the PEO core and PCL- $b$-PEG or PLGA shell material combinations, and are further collected in a uniaxially aligned form on a rotating collector. Two axon-mimicking MRI phantoms are constructed from these anisotropic hollow microfibres after inserting them into water-filled test tubes and are tested on a 7 tesla pre-clinical MR scanner, in order to determine water diffusion behaviour in these two phantoms.

\section{Materials and Methods}

\subsection{Materials}

PLGA (ester terminated, weight-averaged molecular weight $\mathrm{Mw} 50 \mathrm{k}-75 \mathrm{k} \mathrm{g} \mathrm{mol}^{-1}$ and $190-240 \mathrm{k} \mathrm{g} \mathrm{mol}^{-}$ 1, lactide:glycolide 85:15 (molar ratio), labelled as PLGA-I and PLGA-II, respectively), and PEO (viscosity-average molecular weight $\mathrm{Mv}=900 \mathrm{k}$ ) were obtained from Sigma-Aldrich (Dorset, UK). The PCL- $b$-PEG polymer was synthesized from PCL with $\mathrm{Mn}=80 \mathrm{k} \mathrm{g} \mathrm{mol}^{-1}$ and PEG with $\mathrm{Mn}=400$, $1000 \mathrm{~g} \mathrm{~mol}^{-1}$ in Soochow University (China) using a previously described method [25], generating two molecular weights (PCL- $b$-PEG400, and PCL- $b$-PEG1000). Chloroform $\left(\mathrm{CHCl}_{3}\right)$, N,N dimethylformamide (DMF) and tetrahydrofuran (THF) were also purchased from Sigma Aldrich (Dorset, UK). Deionized water or chloroform was used to dissolve PEO.

\subsection{Electrospinning of PCL- $b$-PEG and PLGA polymers}

PCL- $b$-PEG400 was dissolved in a mixed solvent of $\mathrm{CHCl}_{3}$ and DMF at concentrations of $20 \mathrm{wt} . \%$, 25 wt. $\%$ and 30 wt.\% (sets 1-3, Table 1) to determine the spinnability of the PCL-PEG copolymer. PCL- $b$-PEG1000 was also dissolved in a mixed solvent of $\mathrm{CHCl}_{3} / \mathrm{DMF}$ at concentrations of $10 \mathrm{wt} . \%$ and $15 \mathrm{wt} . \%$ (set 4, Table 1). PLGA-I was dissolved in $\mathrm{CHCl}_{3} / \mathrm{DMF}$ with variable blending ratios (sets 5-7, Table 1) and in 5/5 w/w THF/DMF (set 8, Table 1) at a concentration of $20 \mathrm{wt} . \%$. To further explore the effect of the solvents used above, PLGA-II polymer, which has a higher molecular weight than PLGA-I, was dissolved in $8 / 2 \mathrm{w} / \mathrm{w} \mathrm{CHCl}_{3} / \mathrm{DMF}$ at concentration of $20 \mathrm{wt} . \%$ (set 9, Table 1) and $5 / 5 \mathrm{w} / \mathrm{w}$ THF/DMF with three concentrations of 10,15 to $20 \mathrm{wt} . \%$ (set 10, Table 1).

These PCL- $b$-PEG and PLGA polymer solutions were processed under various process parameters listed in Table 1 into fibres on an electrospinning setup schematically shown by Fig.1(a) below and described previously [12]. The investigated polymer solutions and the corresponding process parameters are summarized in Table 1. In brief, a mixed solvent of $\mathrm{CHCl}_{3} / \mathrm{DMF}(8 / 2, \mathrm{w} / \mathrm{w})$ was used 
to dissolve PCL- $b$-PEG at concentrations of 20, 25 and $30 \mathrm{wt}$.\%. PLGA-I and -II were also dissolved in $\mathrm{CHCl}_{3} / \mathrm{DMF}(8 / 2,7 / 3$ and 5/5, w/w) and THF/DMF $(5 / 5, \mathrm{w} / \mathrm{w})$ at the concentrations of 10,15 , and 20 wt.\%. A high-voltage power supply (PS/FC30R04.0e22, Glassman High Voltage, UK) was used to tune the applied voltage between 0 and $30 \mathrm{kV}$. A $10 \mathrm{~mL}$ plastic syringe with a stainless-steel needle (inner diameter $1.19 \mathrm{~mm}$ ) mounted on a syringe pump (SP230IWZ, Multi-Syringe Pump, World Precision Instruments, UK) was used to feed polymer solution to the needle tip at a controllable feed rate (see Table 1 below). The fabricated fibres were then collected either on a glass slide on the top of a grounded metal plate for optical microscopy or on grounded aluminium foil for scanning electron microscopy (SEM). All experiments were conducted in a fume cupboard under ambient conditions. The corresponding cone-jet state observed by the naked eye for the first 10-15 min in each operatiaon and the resultant fibre morphogy based on optical or electron microcopy are also briefly describled in

Table 1.

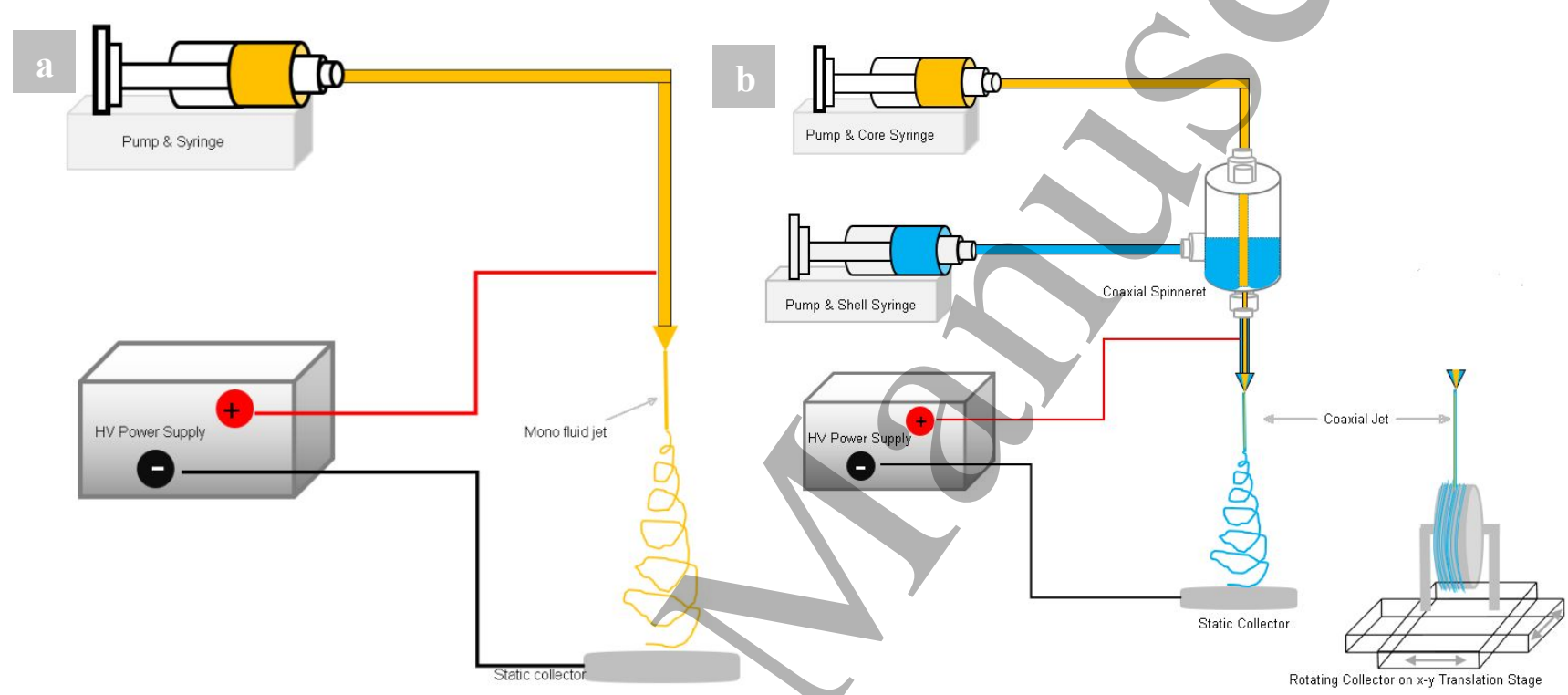

Figure 2. Schematic diagrams of (a) electrospinning using a static collector and (b) coelectrospinning of using static and rotating collectors.

Table 1. Summary of solutions and process parameters in electrospinning experiment. (Temperature of the environment was 20-24 degrees C; humidity was 28-38\%)

\begin{tabular}{|c|c|c|}
\hline Set & Polymer solution & $\begin{array}{c}\text { Process parameters } \\
\text { (applied voltage/working } \\
\text { distance/flow rate) }\end{array}$ \\
\hline 1 & $\begin{array}{c}20 \text { wt. } \% \text { PCL- } b \text {-PEG400 in } \\
\mathrm{CHCl}_{3} / \mathrm{DMF}(8 / 2, \mathrm{w} / \mathrm{w})\end{array}$ & $\begin{array}{l}10 \mathrm{kV} / 15 \mathrm{~cm} / 3.0 \mathrm{~mL} / \mathrm{h} \\
16 \mathrm{kV} / 15 \mathrm{~cm} / 0.6 \mathrm{~mL} / \mathrm{h}\end{array}$ \\
\hline & $\begin{array}{l}25 \mathrm{wt}^{\circ} \% \text { PCL- } b \text {-PEG400 in } \\
\mathrm{CHCl}_{3} / \mathrm{DMF}(8 / 2, \mathrm{w} / \mathrm{w})\end{array}$ & $\begin{array}{c}8 \mathrm{kV} / 15 \mathrm{~cm} / 0.2 \mathrm{~mL} / \mathrm{h} \\
8 \mathrm{kV} / 15 \mathrm{~cm} / 0.4 \mathrm{~mL} / \mathrm{h} \\
11 \mathrm{kV} / 15 \mathrm{~cm} / 0.4 \mathrm{~mL} / \mathrm{h}\end{array}$ \\
\hline 3 & $\begin{array}{c}30 \mathrm{wt} . \% \text { PCL- } b \text {-PEG400 in } \\
\mathrm{CHCl}_{3} / \mathrm{DMF}(8 / 2, \mathrm{w} / \mathrm{w})\end{array}$ & $\begin{array}{l}10 \mathrm{kV} / 15 \mathrm{~cm} / 0.4 \mathrm{~mL} / \mathrm{h} \\
12 \mathrm{kV} / 15 \mathrm{~cm} / 0.8 \mathrm{~mL} / \mathrm{h} \\
12 \mathrm{kV} / 15 \mathrm{~cm} / 1.0 \mathrm{~mL} / \mathrm{h}\end{array}$ \\
\hline 4 & $\begin{array}{c}10 \& 15 \text { wt. } \% \text { PCL- } b- \\
\text { PEG1000 in } \mathrm{CHCl}_{3} / \mathrm{DMF} \\
(8 / 2, \mathrm{w} / \mathrm{w})\end{array}$ & $\begin{array}{l}10 \mathrm{kV} / 10 \mathrm{~cm} / 1.0 \mathrm{~mL} / \mathrm{h} \\
12 \mathrm{kV} / 10 \mathrm{~cm} / 1.0 \mathrm{~mL} / \mathrm{h} \\
15 \mathrm{kV} / 10 \mathrm{~cm} / 1.0 \mathrm{~mL} / \mathrm{h} \\
10 \mathrm{kV} / 12 \mathrm{~cm} / 1.0 \mathrm{~mL} / \mathrm{h} \\
10 \mathrm{kV} / 15 \mathrm{~cm} / 1.0 \mathrm{~mL} / \mathrm{h}\end{array}$ \\
\hline
\end{tabular}


$10 \mathrm{kV} / 10 \mathrm{~cm} / 1.2 \mathrm{~mL} / \mathrm{h}$

$10 \mathrm{kV} / 10 \mathrm{~cm} / 1.5 \mathrm{~mL} / \mathrm{h}$

\begin{tabular}{|c|c|c|}
\hline 5 & $\begin{array}{c}20 \text { wt.\% PLGA-I in } \\
\mathrm{CHCl}_{3} / \mathrm{DMF}(8 / 2, \mathrm{w} / \mathrm{w})\end{array}$ & $\begin{array}{c}13.5 \mathrm{kV} / 13.5 \mathrm{~cm} / 0.3 \mathrm{~mL} / \mathrm{h} \\
15 \mathrm{kV} / 13.5 \mathrm{~cm} / 0.3 \mathrm{~mL} / \mathrm{h} \\
17 \mathrm{kV} / 13.5 \mathrm{~cm} / 0.3 \mathrm{~mL} / \mathrm{h} \\
15 \mathrm{kV} / 13.5 \mathrm{~cm} / 0.05 \mathrm{~mL} / \mathrm{h}\end{array}$ \\
\hline 6 & $\begin{array}{l}20 \text { wt.\% PLGA-I in } \\
\mathrm{CHCl}_{3} \text { /DMF (7/3, w/w) }\end{array}$ & $15.0 \mathrm{kV} / 14 \mathrm{~cm} / 1 \mathrm{~mL} / \mathrm{h}$ \\
\hline 7 & $\begin{array}{c}20 \text { wt.\% PLGA-I in } \\
\mathrm{CHCl}_{3} / \mathrm{DMF}(5 / 5, \mathrm{w} / \mathrm{w})\end{array}$ & $12.9 \mathrm{kV} / 14 \mathrm{cn}$ \\
\hline 8 & $\begin{array}{l}20 \text { wt.\% PLGA-I in } \\
\text { THF/DMF }(5 / 5, \mathrm{w} / \mathrm{w})\end{array}$ & $14 \mathrm{kV} / 14$ \\
\hline 9 & $\begin{array}{c}20 \text { wt.\% PLGA-II in } \\
\mathrm{CHCl}_{3} / \mathrm{DMF}(8 / 2, \mathrm{w} / \mathrm{w})\end{array}$ & $7.7 \mathrm{kV} / 7.5$ \\
\hline 10 & $\begin{array}{l}\text { 10, } 15 \& 20 \text { wt. } \% \text { PLGA-II } \\
\text { in THF/DMF }(5 / 5, w / w)\end{array}$ & $7.5 \mathrm{kV} / 7$ \\
\hline
\end{tabular}

\subsection{Co-electrospinning of PCL-b-PEG and PLGA polymers}

The shell/core solutions and process parameters for co-electrospinning are given in Table 2 . Specifically, 15 wt.\% PCL-b-PEG1000/ $\mathrm{CHCl}_{3}+\mathrm{DMF}$ and $4 \mathrm{wt} . \% \mathrm{PEO} /$ water were used as shell and core solutions in the co-electrospinning process. The co-electrospinning of PLGA was first conducted using $20 \mathrm{wt} . \%$ PLGA-I in $\mathrm{CHCl}_{3}+\mathrm{DMF}(8 / 2, \mathrm{w} / \mathrm{w})$ as the shell fluid while the core solution was varied from $4 \mathrm{wt} . \% \mathrm{PEO}$ in water to $2 \mathrm{wt} . \% \mathrm{PEO}$ in $\mathrm{CHCl}_{3}$. In the case of a $4 \mathrm{wt} . \% \mathrm{PEO}$ in water core, two settings for applied voltage/working distance $(15.6 \mathrm{kV} / 13.5 \mathrm{~cm}$ and $10.5 \mathrm{kV} / 5 \mathrm{~cm})$ were used to observe the jet behaviour while the core/shell flow rates were kept at $0.5 / 1.0 \mathrm{~mL} / \mathrm{h}$. The experimental set-up schematically shown in Fig. $2 \mathrm{~b}$ used for preparing hollow microfibres has been described previously [12]. In brief, a coaxial spinneret, with two concentric needles (ID 0.41 and $1.19 \mathrm{~mm}$ ), was filled with a shell solution of PCL-b-PEG or PLGA (outer needle) and a core solution of PEO (inner needle). The outer needle was connected to the positive electrode from a DC high voltage power supply (as was the case for the electrospinning above). The fibre collector, which was placed below the tip of the concentric needles, was connected to the grounded electrode.

Those parameters listed in Table 2, guaranteeing a reasonably stable co-electrospinning process, were reached after a series of optimizations with respect to the solvent system, polymer concentrations, flow rate and applied voltage. A wide rotating drum $(\sim 11 \mathrm{~cm}$ in diameter), which was spun at controllable revolutions per minute (rpm), was used as a collector to align the fibres. Once the inner core solution in the deposited fibres evaporated, which takes a few milliseconds [26], the hollow fibres were left with a solidified outer sheath. All experiments were conducted in a fume cupboard at ambient conditions. A solution of PCL- $b$-PEG or PLGA polymer in $\mathrm{CHCl}_{3} / \mathrm{DMF}$ or THF/DMF solvent was used as the shell fluid and PEO in deionized water or $\mathrm{CHCl}_{3}$ acted as the core fluid. These two liquids were fed at a constant flow rate independently controlled by two syringe pumps.

\subsection{Optical and scanning electron microscopy}


The morphology of electrospun and co-electrospun fibres was observed using an Olympus BH2-UMA optical microscope and a Philips XL30 FEG scanning electron microscope (SEM) or a Phenom G2 pro desktop SEM with an accelerating voltage of $5 \mathrm{kV}$. In order to quickly determine the morphology of electrospun products, a glass slide was introduced into the electrospinning/co-electrospinning setup and held in contact with the grounded collector, in the centre of the spinning zone for a short period of time (usually less than one minute) at the beginning of the process. These were imaged using optical microscopy. The electrospun fibres collected on aluminium foil were coated with a thin layer of palladium-gold with a thickness of approximately $10 \mathrm{~nm}$ to increase their conductivity before SEM imaging. For imaging of fibre cross sections using SEM, fibres were first cut by sharp scissors in liquid nitrogen. For the quantitative analysis of the pores of co-electrospun hollow fibres, ImageJ/was used for analysis based on a previously reported semi-automated method with Size and Circularity setting to be 0.5-15 $\mu \mathrm{m}$ and 0.001-1.00, respectively in "Analyze Particle" feature [16].

\section{5. dMRI phantom construction}

One PCL- $b$-PEG fibre phantom sample from the co-electrospun hollow PCL- $b$-PEG fibre strip (set 1, Table 2) and one PLGA fibre phantom sample were constructed from hollow PLGA fibre strip (set 5, Table 2), respectively. Two layers of PCL- $b$-PEG fibre strips of $\sim 2.0 \mathrm{~mm}$ thick and 6 layers of PLGA fibre strips of $\sim 0.35 \mathrm{~mm}$ thick, respectively, were packed into two $12 \mathrm{~mm}$ outer diameter (O.D.) glass tubes (Wilmad-LabGlass) that were filled with deionized water.

\subsection{MR imaging}

The resultant phantoms were immersed in water for about one week before MR scanning to ensure water permeation of all pores. Three test tubes (two containing fibre phantoms immersed in water, one containing only water) were placed inside a transmit/receive volume coil and were scanned on a $7 \mathrm{~T}$ horizontal bore magnet (Magnex Scientific Ltd., Abingdon, UK) interfaced to a Bruker Avance III console (Bruker BioSpin, Ettlingen, Germany). Diffusion tensor imaging (DTI) was performed using a pulsed gradient spin-echo sequence with 6 diffusion sensitisation directions, $b=0,1000 \mathrm{~s} / \mathrm{mm}^{2}, \partial=$ $4 \mathrm{~ms}, \Delta=12 \mathrm{~ms}, \mathrm{TE}=22.5 \mathrm{~ms}$, TR $=1500 \mathrm{~ms}$, field of view $=30 \mathrm{~mm} \times 30 \mathrm{~mm}$, matrix $=128 \times 128$, $1 \mathrm{~mm}$ slice thickness, 10 axial slices. The in-plane resolution of DTI slices was $0.23 \mathrm{~mm} \times 0.23 \mathrm{~mm}$. The data were processed using DSI Studio (dsi-studio.labsolver.org) to generate mean diffusivity (MD) and fractional anisotropy (FA) maps. MD and FA values in the phantoms were obtained from regions of interest (ROIs) defined by thresholding the $b=0 \mathrm{~s} / \mathrm{mm}^{2}$ images to separate the phantom material from the surrounding water; values in the water-only tube were obtained from circular ROIs.

Table 2. Summary of shell/core solutions and process parameters in co-electrospinning. (Typical temperature of the environment was 20-24 degrees C, typical humidity was $28-38 \%$ )

Process parameters

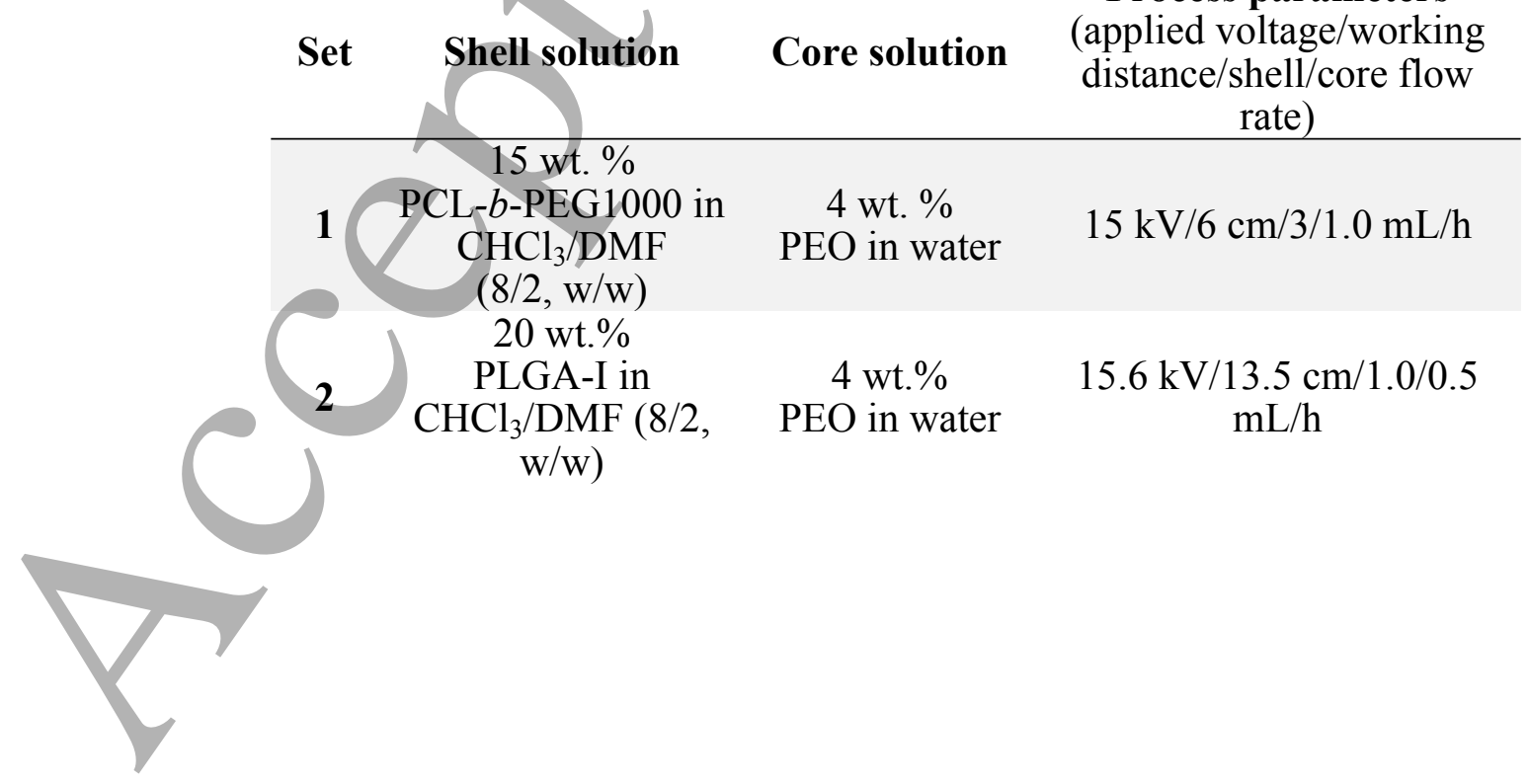


$10.5 \mathrm{kV} / 5 \mathrm{~cm} / 1.0 / 0.5$ $\mathrm{mL} / \mathrm{h}$

20 wt.\%

PLGA-I in $2 \mathrm{wt} . \%$

3

$\mathrm{CHCl}_{3} / \mathrm{DMF}\left(8 / 2, \quad \mathrm{PEO}\right.$ in $\mathrm{CHCl}_{3}$ $\mathrm{w} / \mathrm{w}$ )

$20 \mathrm{wt.} \%$

4 PLGA-I in

$\mathrm{CHCl}_{3} / \mathrm{DMF}\left(5 / 5, \quad \mathrm{PEO}\right.$ in $\mathrm{CHCl}_{3}$ $\mathrm{w} / \mathrm{w})$ 20 wt. $\%$

5 PLGA-I in

THF/DMF(5/5, PEO in $\mathrm{CHCl}_{3}$ $\mathrm{w} / \mathrm{w})$ 20 wt. $\%$ PLGA-

$6 \quad \mathrm{II} / \mathrm{CHCl}_{3}+\mathrm{DMF}$ $(8 / 2, w / w)$

\section{$2 \mathrm{wt} . \%$} $\mathrm{PEO}$ in $\mathrm{CHCl}_{3}$

$10.5 \mathrm{kV} / 5 \mathrm{~cm} / 1 / 0.5 \mathrm{~mL} / \mathrm{h}$

$10.5 \mathrm{kV} / 5 \mathrm{~cm} / 0.5 / 0.5$ $\mathrm{mL} / \mathrm{h}$
$10.5 \mathrm{kV} / 5 \mathrm{~cm} / 1 / 0.5 \mathrm{~mL} / \mathrm{h}$

$10 \mathrm{kV} / 10 \mathrm{~cm} / 0.1 / 0.1 \mathrm{~mL} / \mathrm{h}$
$10.5 \mathrm{kV} / 5 \mathrm{~cm} / 0.5 / 0.5 \mathrm{~mL} / \mathrm{h}$

20 wt.\%

PLGA-II in

7 THF/DMF (5/5, $\mathrm{w} / \mathrm{w})$

2 wt.\% $\mathrm{PEO}$ in $\mathrm{CHCl}_{3}$

$$
\text { (1) }
$$

\section{Results and discussion}

The present work primarily reported the microstructures of copolymer fibres via electrospinning and co-electrospinning, and water diffusion behaviour in hollow microfibres, but nevertheless wettability and physico-chemical properties of copolymers as reported in previous studies [18, 25] are important for the resultant fibre phantoms.

\subsection{Electrospinning of PCL-b-PEG copolymers}

Solution dripping was observêd and became less frequent with increasing applied voltage or decreasing flow rate (set 1, Table 1). As shown in Fig. 3a-b, mixed structures comprising beaded PCL-b-PEG fibres with diameters up to a few microns and bead-free fibres with much thinner diameters (a few hundred nanometres) are present in the product from a $20 \mathrm{wt} . \%$ solution; the processes in sets 2-3 (Table 1) were stable; but fibres from $25 \mathrm{wt} \%$ (Fig. 3c-e) and $30 \mathrm{wt}$ \% (Fig. 3f-h) solutions are relatively smooth and nearly bead-free but micro-sized fibres are more likely to be formed from $30 \mathrm{wt} . \%$ concentration especially when a relatively high flow is used. 

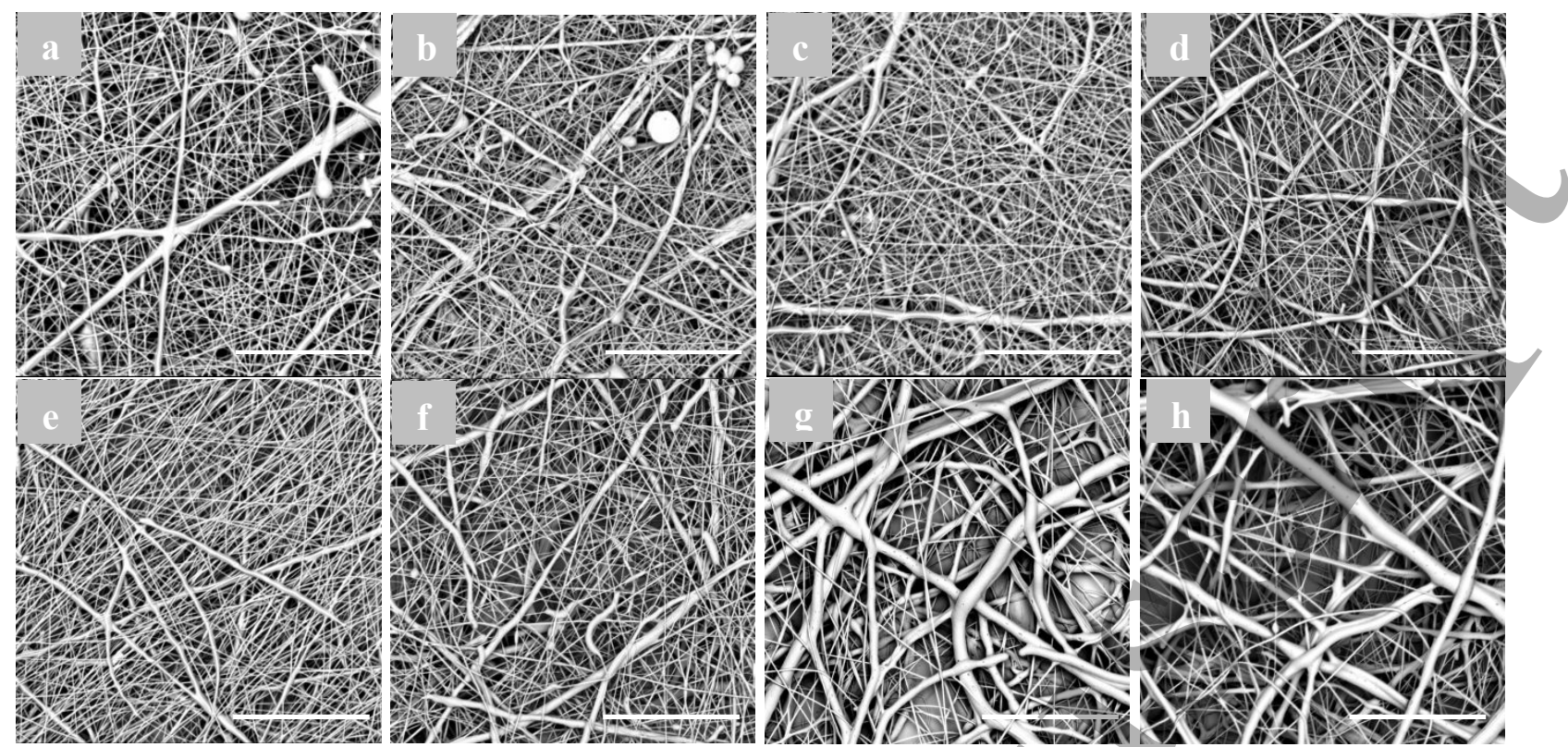

Figure 3. SEM micrographs of electrospun fibres generated from PCL-co-PEG400 solutions with various concentrations and process parameters (sets 1-3, Table 1). (a) $20 \mathrm{wt} . \%, 10 \mathrm{kV} / 15 \mathrm{~cm} / 3.0 \mathrm{~mL} / \mathrm{h}$ (set 1, Table 1); (b) $20 \mathrm{wt} . \%, 16 \mathrm{kV} / 15 \mathrm{~cm} / 0.6 \mathrm{~mL} / \mathrm{h}$ (set 1); (c) $25 \mathrm{wt} . \%, 8 \mathrm{kV} / 15 \mathrm{~cm} / 0.2 \mathrm{~mL} / \mathrm{h}$ (set 2); (d) $25 \mathrm{wt} . \%, 8 \mathrm{kV} / 15 \mathrm{~cm} / 0.4 \mathrm{~mL} / \mathrm{h}$, (set 2); (e) $25 \mathrm{wt} . \%, 11 \mathrm{kV} / 15 \mathrm{~cm} / 0.4 \mathrm{~mL} / \mathrm{h}$ (set 2); (f) $30 \mathrm{wt} . \%, 10$ $\mathrm{kV} / 15 \mathrm{~cm} / 0.4 \mathrm{~mL} / \mathrm{h}$, (set 3); (g) $30 \mathrm{wt} . \%, 12 \mathrm{kV} / 15 \mathrm{~cm} / 0.8 \mathrm{~mL} / \mathrm{h}$, (set 3); (h) $30 \mathrm{wt} . \%, 12 \mathrm{kV} / 15$ $\mathrm{cm} / 1.0 \mathrm{~mL} / \mathrm{h}$ (set 3). Scale bars: $20 \mu \mathrm{m}$.

Solution dripping occurred to $10 \mathrm{wt} . \%$ but not to $15 \mathrm{wt} . \%$ solution in set 4 , Table 1 ; beaded fibres and bead-free fibre formed from 10 wt.\% (Fig. 4a-g), and 15 wt.\% (Fig. 4h-n), respectively. As shown in Fig. 4a-g, beaded PCL fibres are present in the products electrospun from the $10 \mathrm{wt} \%$ solution regardless of the changing process parameters; fibres produced from $15 \mathrm{wt}$.\% are bead-free (Fig. $\mathbf{4 h}$ n) and have much larger sizes than those obtained from $10 \mathrm{wt} . \%$. When the high flow rate of $1.5 \mathrm{~mL} / \mathrm{h}$ was used, the resultant fibres (Fig. n) look much thicker (up to ca. $10 \mu \mathrm{m}$ ) than those produced under other conditions, and tend to merge. These thicker and merged fibres are expected to be caused by the insufficient jet stretching in the electrospinning process.
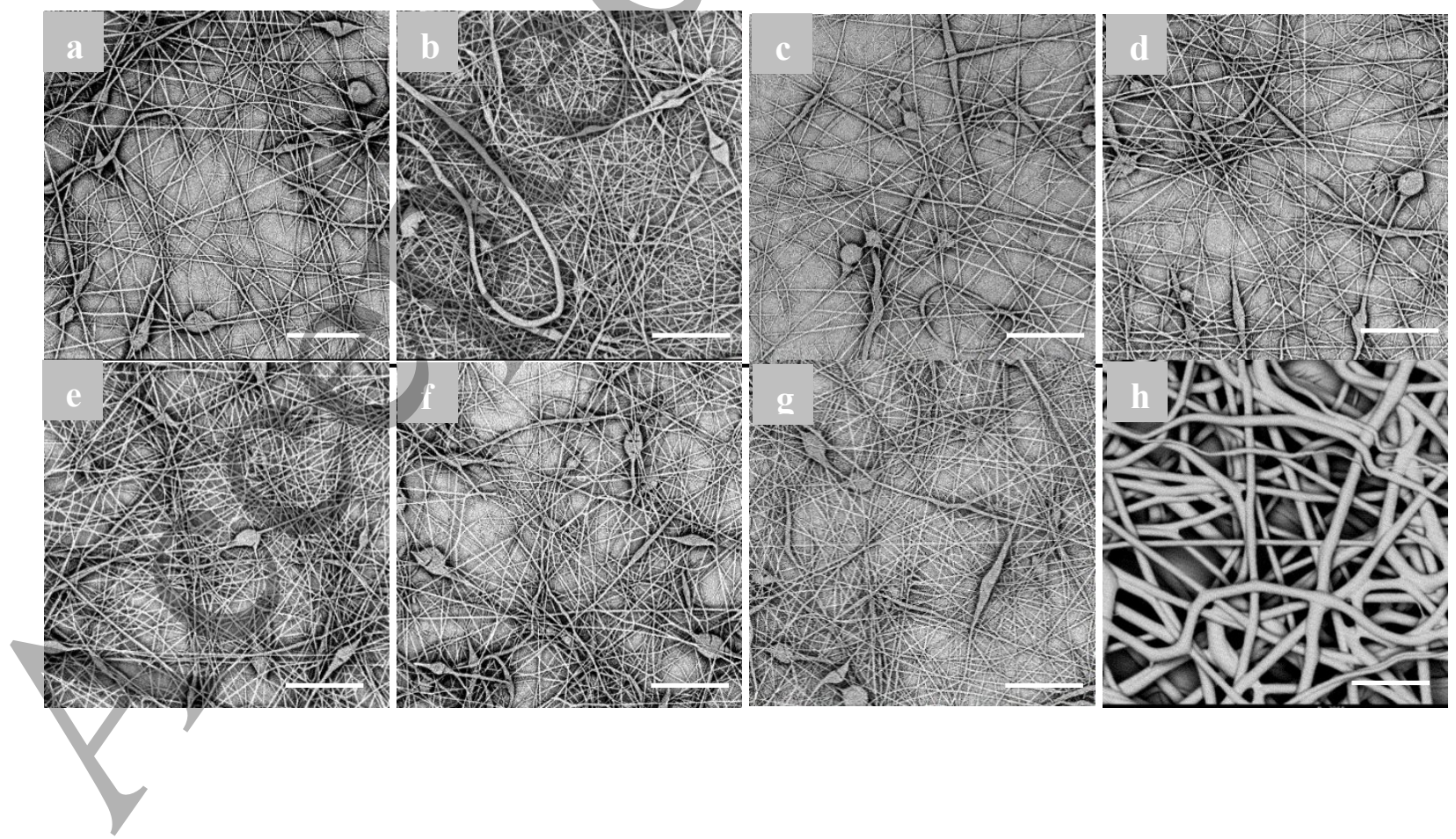

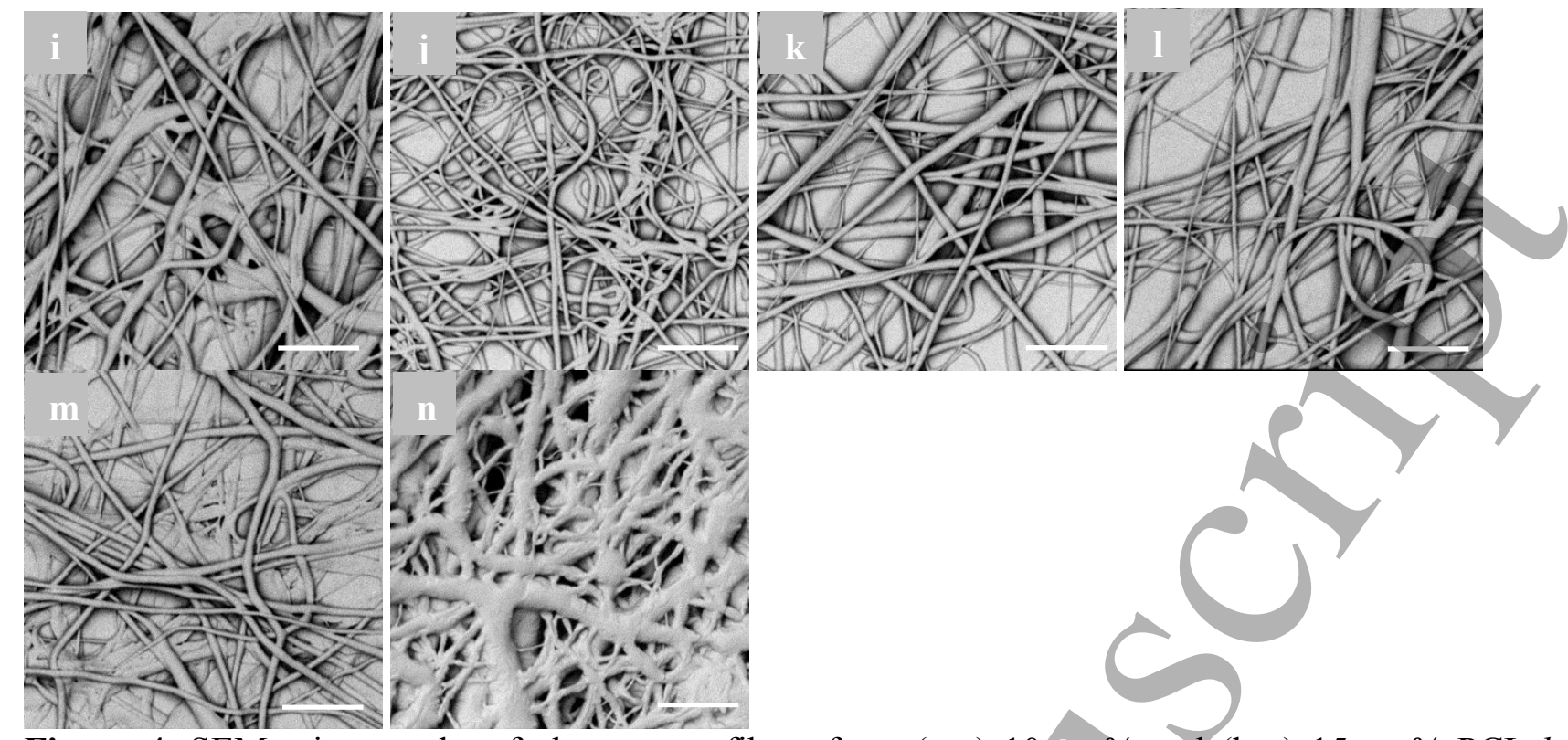

Figure 4. SEM micrographs of electrospun fibres from (a-g) 10 wt. $\%$ and (h-n) 15 wt.\% PCL- $b$ PEG1000 in $\mathrm{CHCl}_{3} / \mathrm{DMF}$ via process parameters (set 4, Table 1): (a) $10 \mathrm{kV} / 10 \mathrm{~cm} / 1.0 \mathrm{~mL} / \mathrm{h}$; (b) 12 $\mathrm{kV} / 10 \mathrm{~cm} / 1.0 \mathrm{~mL} / \mathrm{h}$;(c) $15 \mathrm{kV} / 10 \mathrm{~cm} / 1.0 \mathrm{~mL} / \mathrm{h}$; (d) $10 \mathrm{kV} / 12 \mathrm{~cm} / 1.0 \mathrm{~mL} / \mathrm{h}$; (e) $10 \mathrm{kV} / 15 \mathrm{~cm} / 1.0 \mathrm{~mL} / \mathrm{h}$;(f) $10 \mathrm{kV} / 10 \mathrm{~cm} / 1.2 \mathrm{~mL} / \mathrm{h} ;(\mathrm{g}) 10 \mathrm{kV} / 10 \mathrm{~cm} / 1.5 \mathrm{~mL} / \mathrm{h}$. Scale bars: $20 \mu \mathrm{m}$.

PCL- $b$-PEG copolymers are synthesised by grafting active sites of hydroxyl groups to PCL chains via aminolysis, leading to products with controllable molecular weight and significantly improved water wettability of PCL alone [25]. The PCL- $b$-PEG400 and PCL- $b$-PEG1000 polymers are here for the first time demonstrated to be eletrospinnable under appropriate combinations of solution concentration and key process parameters. The combination of wettability and spinnability for PCL- $b$-PEG makes it a potentially useful material for creating axon-mimicking phantoms via co-electrospinning [18]. Due to the fibre size and lack of beading, $15 \mathrm{wt}$.\% PCL- $b$-PEG1000 in $\mathrm{CHCl}_{3}$ was chosen here to be used as the shell solution in the co-electrospinning of axon-mimicking fibres in Section 3.3.

\subsection{Electrospinning of PLGA copolymers}

An increase in applied voltage from 13.5 to $17 \mathrm{kV}$ or a decrease in flow rate from 0.3 to $0.05 \mathrm{~mL} / \mathrm{h}$ helped achieve a stable process. All the resultant PLGA-I fibres are bead-free and uniform in size (a few microns in diameter) (Supplementary information, Fig. S1a-d), both when the applied voltage is changed from $13.5 \mathrm{kV}$ to $17.0 \mathrm{kV}$ and the flow rate was reduced from $0.3 \mathrm{~mL} / \mathrm{h}$ to $0.05 \mathrm{~mL} / \mathrm{h}$ in set 5 . This indicates that the spinnability of the $20 \mathrm{wt} . \%$ solution PLGA-I in $\mathrm{CHCl}_{3} / \mathrm{DMF}(8 / 2, \mathrm{w} / \mathrm{w})$ is good, allowing fibre formation within a range of electric field strengths and/or flow rates. Solution was slightly dripping when changing the blend ratio of $\mathrm{CHCl}_{3} / \mathrm{DMF}$ from $8 / 2$ to $7 / 3 \mathrm{w} / \mathrm{w}$ (set 6 ). There is an obvious change in morphology from smooth to beaded fibres on which the bead size could reach ca. $40 \mu \mathrm{m}$ diameter (Supplementary information, Fig. S1e). Solution dripping disappeared when the proportion of DMF increased $\left(\mathrm{CHCl}_{3} / \mathrm{DMF}\right.$ ratio from $7 / 3$ to $5 / 5 \mathrm{w} / \mathrm{w}$, set 7$)$. Beaded fibres become dominant (Supplementary information, Fig. S1f ). A similar morphology transition caused by the solvent composition was observed in a previous study [27]. Both $\mathrm{CHCl}_{3}$ and $\mathrm{DMF}$ are good solvents for the PLGA polymer but DMF has a higher evaporation rate and surface tension, which favours the formation of the beads or beaded fibres. When $5 / 5 \mathrm{w} / \mathrm{w}$ THF/DMF was used as the solvent (set 8 ), a stable process was achieved. PLGA fibres become defect-free and smoother (Supplementary information, Fig. S1g) than those fibres from 5/5 w/w $\mathrm{CHCl}_{3} / \mathrm{DMF}$ (Supplementary information, Fig. S1f), indicating that the presence of THF favours the formation of smooth PLGA fibres compared with $\mathrm{CHCl}_{3}$ when the blending ratio is kept at $5 / 5 \mathrm{w} / \mathrm{w}$. This result is consistent with a previous study in which PLGA in THF/DMF formed smoother fibres than those from a PLGA solution in $\mathrm{CHCl}_{3} / \mathrm{DMF}$ 
with the same polymer concentration [27]. This could be explained by the fact that the surface tension of PLGA in $\mathrm{CHCl}_{3} / \mathrm{DMF}$ is significantly higher than THF/DMF, which can promote the formation of beaded fibres from the former case [27].

The electrospinning process of 20 wt.\% PLGA-II in $\mathrm{CHCl}_{3} / \mathrm{DMF}(8 / 2, \mathrm{w} / \mathrm{w})$ (set 9$)$ or THF/DMF (5/5, $\mathrm{w} / \mathrm{w}$ ) (set 10) was found be stable but became not for 10 and $15 \mathrm{wt} . \%$ PLGA-II in THF/DMF (5/5, $\mathrm{w} / \mathrm{w}$ ) (set 10). The resultant fibres from PLGA-II in $8 / 2 \mathrm{w} / \mathrm{w} \mathrm{CHCl} / 2 / \mathrm{DMF}$ have defect-free morphology (Supplementary information, Fig. S1h), which looks similar to those fibres from PLGA-I in this solvent system (Supplementary information, Fig. S1a-d). When the solvent system was THF/DMF (5/5, w/w), the resultant PLGA fibre morphology changed from beaded to bead-free (Supplementary information, Fig. S1i-k) with the increasing polymer concentration while the process parameters were kept constant.

As with the PCL- $b$-PEG copolymer, these results demonstrate that both PLGA-I and II can also be processed into smooth and uniform fibres using appropriate solvent/systems. Diffusion MRI has revealed that water can penetrate into tumour cell-mimicking phantom comprising hollow PLGA microspheres of [28]. Therefore, the spinnability and wettability of PLGA polymers could enable them to be another suitable shell material in the co-electrospinning of axon-mimicking fibres.

\subsection{Co-electrospinning of PCL-b-PEG and PLGA hollow microfibres}

Previous study has demonstrated that the co-electrospinning process of $10 \mathrm{wt} . \% \mathrm{PCL} / \mathrm{CHCl} \mathrm{H}_{3}+\mathrm{DMF}$ as shell and $4 \mathrm{wt} . \% \mathrm{PEO} /$ water as core is appropriate to produce hollow PCL microfibres with various sizes that can be used to create axon mimicking phantoms $[12,18,29]$. Similar experimental parameters (except with applied voltage of $15 \mathrm{kV}$ ) to those in these earlier studies were adopted in the co-electrospinning of a $4 \mathrm{wt} . \% \mathrm{PEO} /$ water core and the $15 \mathrm{wt}$. $\%$ PCL- $b$-PEG1000/CHCl $3+\mathrm{DMF}$ shell to generate an aligned fibre bundle on a rotating drum. As shown in Fig.5a-c, the resultant PCL- $b$ PEG fibres in the bundle are predominantly aligned (as indicated by the arrow) and hollow.

In both processes the compound fluid jet was found to be stable and straight over an observation period of $\sim 1 \mathrm{~h}$. In the case of $2 \mathrm{wt} . \% \mathrm{PEO}$ in $\mathrm{CHCl}_{3}$ core, a straight and stable fluid jet was also achieved for an operation period of $\sim 1 \mathrm{~h} 45 \mathrm{~min}$. However, over a longer period of co-electrospinning, solidified PLGA polymer was seen gradually accumulating on the needle tip and finally blocked the needle, resulting in short interruptions of the process stability. The co-electrospinning process resumed and was stable after manually removing the solidified polymer from the needle tip.

As shown in in Fig. 5d-f, the resultant PLGA-I fibres generated from both PEO in water and PEO in $\mathrm{CHCl}_{3}$ cores have a flat ribbon structure. A representative cross-sectional micrograph in Fig. $\mathbf{5 g}$ further reveals that PLGA-I fibres do not have hollow and circular structure. A change in the blending ratio of $\mathrm{CHCl}_{3} / \mathrm{DMF}$ from $8 / 2$ to $7 / 3$ or $5 / 5 \mathrm{w} / \mathrm{w}$ (giving a lower evaporation rate) was found to prevent the solidification of the PLGA solution. However, the decreasing $\mathrm{CHCl}_{3}$ content favoured the formation of beaded fibres (Fig. 5h) collected on a glass slide in the co-electrospinning. The use of 5/5 THF/DMF solvent for PLGA-I was found to be very effective in changing the morphology from beaded to smooth fibres (Fig. 5i). This morphological change is not surprising because in electrospinning beaded fibres were generated from $20 \mathrm{wt}$.\% PLGA-I in $7 / 3$ or $5 / 5 \mathrm{w} / \mathrm{w} \mathrm{CHCl}_{3} / \mathrm{DMF}$ (Fig. $4 \mathbf{e}$ and $\mathbf{f}$ ) but smooth fibres were from 20 wt.\% PLGA-I in 5/5 w/w THF/DMF (Fig. 4g). For the combination of a PEO in $\mathrm{CHCl}_{3}$ core and PLGA-I in 8/2 w/w $\mathrm{CHCl}_{3} / \mathrm{DMF}$ shell, a change in the shell flow rate from 1 to $0.5 \mathrm{~mL} / \mathrm{h}$, while other governing process parameters were unchanged (except the collector speed), led to changes in the fibre morphology from collapsed (Fig. 5f) to hollow (Fig. 6a). When the shell was changed to be PLGA-I in $5 / 5 \mathrm{w} / \mathrm{w}$ THF/DMF and other parameters were constant, hollow and aligned PLGA fibres were also seen (Fig. 6b). For the shell solution of PLGA-II in $8 / 2 \mathrm{CHCl}_{3} / \mathrm{DMF}$ or $5 / 5 \mathrm{THF} / \mathrm{DMF}$ 
solvent, the PLGA fibres in the resultant strips were also hollow (Fig. 6c and d) when the same core solution and process parameters were used, except the applied voltage used for PLGA-II in 5/5 THF/DMF. It should be mentioned however that the hollow PLGA fibres in these strips merge with their neighbours and there are also extra-fibre spaces of larger size than the interior of the hollow PLGA fibres, especially for the $8 / 2 \mathrm{CHCl}_{3} / \mathrm{DMF}$ solvent. The cross-sections of PLGA fibre strips from THF/DMF (Fig. 6b and d) appear much denser than those from $\mathrm{CHCl}_{3} / \mathrm{DMF}$ (Fig. 6a and c).
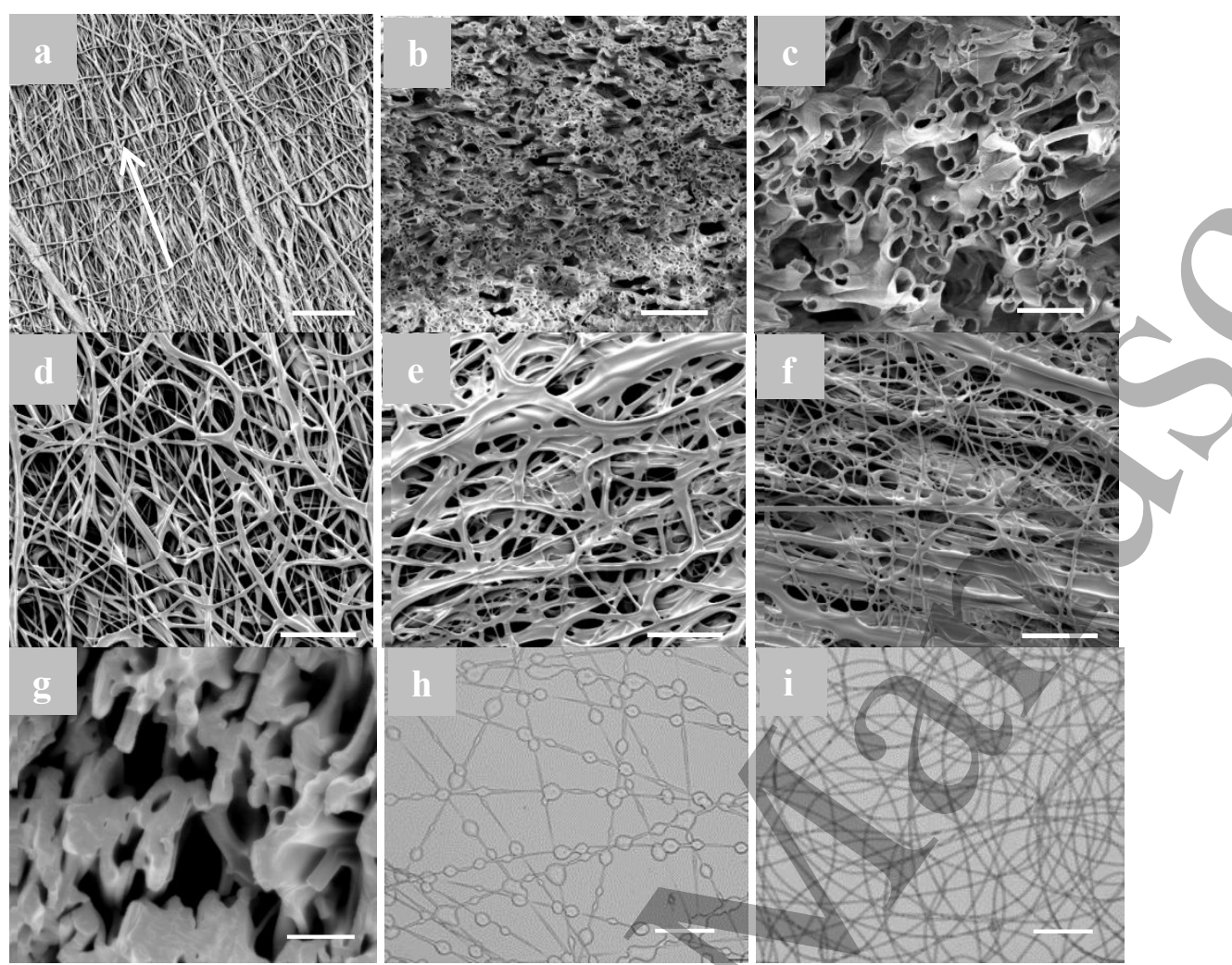

Figure 5. Electron and optical images of co-electrospun PCL- $b$-PEG fibres from (a-c) 15 wt.\% PCL$b$-PEG/CHCl ${ }_{3}+\mathrm{DMF}(8 / 2, \mathrm{w} / \mathrm{w})$ shell and $4 \mathrm{wt} . \% \mathrm{PEO} /$ water core, $3 / 1 \mathrm{~mL} / \mathrm{h}$ shell/core flow rate, 15 $\mathrm{kV}, 6 \mathrm{~cm}$ working distance, $800 \mathrm{rpm}$ collector speed (set 1, Table 2); co-electrospun PLGAI/CHCl ${ }_{3}+\mathrm{DMF}(8 / 2)$ shell using: (d) $1.0 / 0.5 \mathrm{~mL} / \mathrm{h}, 15.6 \mathrm{kV}, 13.5 \mathrm{~cm}, 400 \mathrm{rpm}, 4 \mathrm{wt} . \%$ PEO/water core (set 2, Table 2); (e) $1.0 / 0.5 \mathrm{~mL} / \mathrm{h}, 10.5 \mathrm{kV}, 5 \mathrm{~cm}, 400 \mathrm{rpm}, 4 \mathrm{wt} \%$ PEO/water core (set 2, Table 2); (f) $1.0 / 0.5 \mathrm{~mL} / \mathrm{h}, 10.5 \mathrm{kV}, 5 \mathrm{~cm}, 400 \mathrm{rpm}, 2 \mathrm{wt} . \% \mathrm{PEO} / \mathrm{CHCl}_{3}$ core (set 3, Table 2); (g) crosssection of the fibre sample in (e); (h) co-electrospun PLGA-I/CHCl ${ }_{3}+\mathrm{DMF}(5 / 5)$ shell using $1.0 / 0.5$ $\mathrm{mL} / \mathrm{h}, 10.5 \mathrm{kV}, 5 \mathrm{~cm}, 2 \mathrm{wt} . \% \mathrm{PEO} / \mathrm{CHCl}_{3}$ core (set 4, Table 2); (i) co-electrospun PLGA-I/THF+DMF (5/5), $0.1 / 0.1 \mathrm{~mL} / \mathrm{h}, 10 \mathrm{kV}, 10 \mathrm{~cm}, 2$ wt.\% $\mathrm{PEO} / \mathrm{CHCl}_{3}$ core (set 5, Table 2). Scale bars in (a-c): 50, 100 and $25 \mu \mathrm{m}$, in (d-f): $100 \mu \mathrm{m}$; in (g-i): 20, 100, and $20 \mu \mathrm{m}$. Arrow in (a) indicates the dominant fibre orientation.

In the case of co-electrospinning of a shell of PLGA in $\mathrm{CHCl}_{3} / \mathrm{DMF}$ with a core comprising PEO in water, a straight and stable jet was present not only at $5 \mathrm{~cm}$ working distance, but also at $13.5 \mathrm{~cm}$. When PEO in $\mathrm{CHCl}_{3}$ was used as the core solution, the co-electrospinning process was found to be even more stable than the process using $\mathrm{PEO} /$ water core due to the miscibility between the core and the shell solution, which is consistent with a previous study developing hollow PLGA microfibres using miscible core and shell solutions [30]. In addition to solution properties [31, 32], the shell/core flow rate has been identified as a key parameter determining the stability of the co-electrospinning process and thus the formation and size of the resultant fibres [12, 14, 33, 34]. With core/shell flow rates of $0.5 / 1 \mathrm{~mL} / \mathrm{h}$, the fluid jet did not completely dry when it reached the collector, resulting in the collapse of the fibres. In a previous study on the co-electrospinning of PLGA/THF+DMF $(1: 1, v / v)$ 
shell and $\mathrm{PEO} / \mathrm{CHCl}_{3}+\mathrm{DMF}(1: 2, \mathrm{v} / \mathrm{v})$, equal core and shell flow rates of $0.05 \mathrm{~mL} / \mathrm{h}$ were used to fabricate hollow PLGA microfibres [30].

In addition, a higher molecular weight PLGA in the shell can generate more polymer chain entanglements and therefore contribute to the rapid solidification of the shell and thus the formation of hollow PLGA microfibres, as previously reported in co-electrospinning of hollow polycarbonate microfibres [31]. A higher proportion of DMF in THF/DMF $(5 / 5, \mathrm{w} / \mathrm{w})$ than that in $\mathrm{CHCl}_{3} / \mathrm{DMF}(8 / 2$, $\mathrm{w} / \mathrm{w}$ ) is expected to be responsible for the denser cross sections of PLGA fibre strips in the former case, because its lower evaporation rate could slow down the drying of PLGA fibres. Based on the SEM observation of co-electrospun hollow PCL microfibres [16, 18], there are more distinct structure/appearance differences between PCL and PLGA fibres than those between PCL and PCL- $b$ PEG. In addition, due to the fact that a relatively low shell/core flow rate was required for stable coelectrospinning using PLGA, generating a PLGA fibre strip with a thickness of $\sim 0.35 \mathrm{~mm}$ used to construct an MR phantom took $\sim 11 \mathrm{~h}$, which is much longer than the fabrication of a $\sim 0.5 \mathrm{~mm}$ thick PCL fibre strip $(6 \mathrm{~h})$ in a previous study [29]. The long operation of co-electrospinning required by PLGA fibre phantoms could be reduced via multiple coaxial needles or needleless coaxial spinnerets summarized in [35]. As previously reported in electrospun PCL and PLGA nanofibres [36], the resultant co-electrospun PLGA fibre strips were stiffer and less ductile than PCL and PCL- $b$-PEG fibres, which resulted in the gaps between adjacent layers when compressing several layers of PLGA fibre strips in phantom construction.
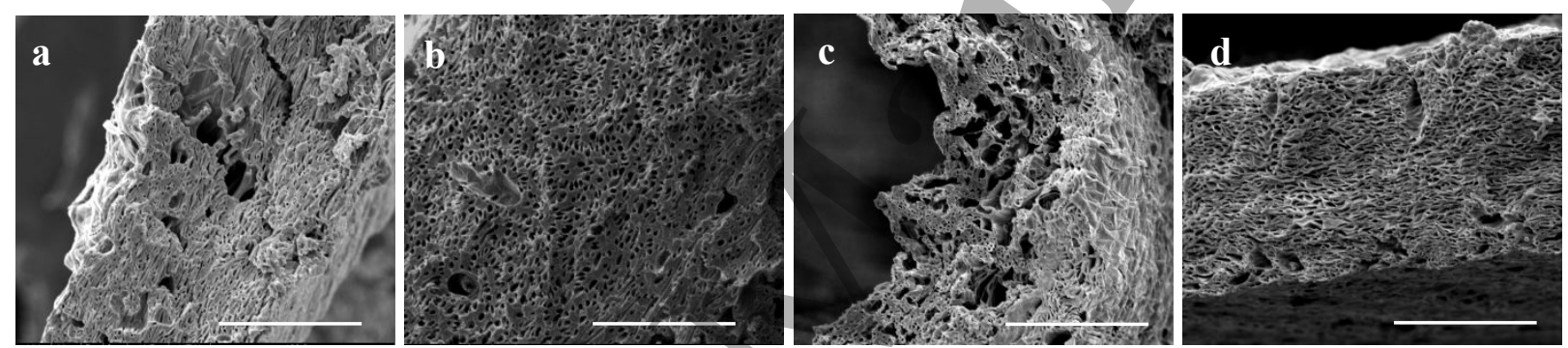

Figure 6. SEM micrographs of co-electrospun PLGA hollow microfibres: (a) 20 wt.\% PLGA$\mathrm{I} / \mathrm{CHCl}_{3}+\mathrm{DMF}(8 / 2, \mathrm{w} / \mathrm{w}), 2 \mathrm{wt} . \% \mathrm{PEO} / \mathrm{CHCl}_{3}$, shell/core flow rate $0.5 / 0.5 \mathrm{~mL} / \mathrm{h}, 10.5 \mathrm{kV}, 5 \mathrm{~cm}, 180$ $\mathrm{rpm}, 1 \mathrm{~mm} / \mathrm{s}$ X-Y stage speed (set 3, Table 2); (b) $20 \mathrm{wt} \%$ PLGA-I/THF+DMF $(5 / 5, \mathrm{w} / \mathrm{w}), 2 \mathrm{wt} . \%$ $\mathrm{PEO} / \mathrm{CHCl}_{3}, 0.5 / 0.5 \mathrm{~mL} / \mathrm{h}, 10.5 \mathrm{kV}, 5 \mathrm{~cm}, 180 \mathrm{rpm}, 1 \mathrm{~mm} / \mathrm{s}$ (set 5, Table 2); (c) 20 wt.\% PLGA$\mathrm{II} / \mathrm{CHCl}_{3}+\mathrm{DMF}\left(8 / 2\right.$, w/w), $2 \mathrm{wt} . \% \mathrm{PEO} / \mathrm{CHCl}_{3}, 0.5 / 0.5 \mathrm{~mL} / \mathrm{h}, 9 \mathrm{kV}, 5 \mathrm{~cm}, 180 \mathrm{rpm}, 1 \mathrm{~mm} / \mathrm{s}$, (set 6, Table 2); (d) 20 wt.\% PLGA-II/THF+DMF (5/5, w/w), 2 wt. $\%$ PEO/CHCl $3,0.5 / 0.5 \mathrm{~mL} / \mathrm{h}, 15 \mathrm{kV}, 5$ $\mathrm{cm}, 180 \mathrm{rpm}, 1 \mathrm{~mm} / \mathrm{s}$ (set 7, Table 2). Scale bars in (a, b, c, d): $100 \mu \mathrm{m}$.

Fig. 7 depicts the box plots showing the median and interquartile range of inter- and intra-fibre pores with diameter from 0.5 to $15 \mu \mathrm{m}$ in the PLGA fibre strips and their corresponding SEM images. As previously explained in the structure of hollow PCL fibre strips [16], the circular or elliptic intra-fibre pores have diameters of a few microns (e.g. $\sim 1-5 \mu \mathrm{m}$ ); in contrast, those inter-fibre pores are either void space with irregular shape and much larger size (e.g. $>\sim 5 \mu \mathrm{m})$ or circular space with much smaller size (e.g. $<\sim 1 \mu \mathrm{m}$ ); four median values of the e pore sizes of hollow microfibres in four combinations of shell/core solutions are in the range of 1-1.6 $\mu \mathrm{m}$; there are fewer outliers in the PLGA fibre strips produced using THF/DMF solvent than those using $\mathrm{CHCl}_{3} / \mathrm{DMF}$, indicating that the use of THF/DMF as solvent can improve the homogeneous microstructure of fibre cross-sections. 


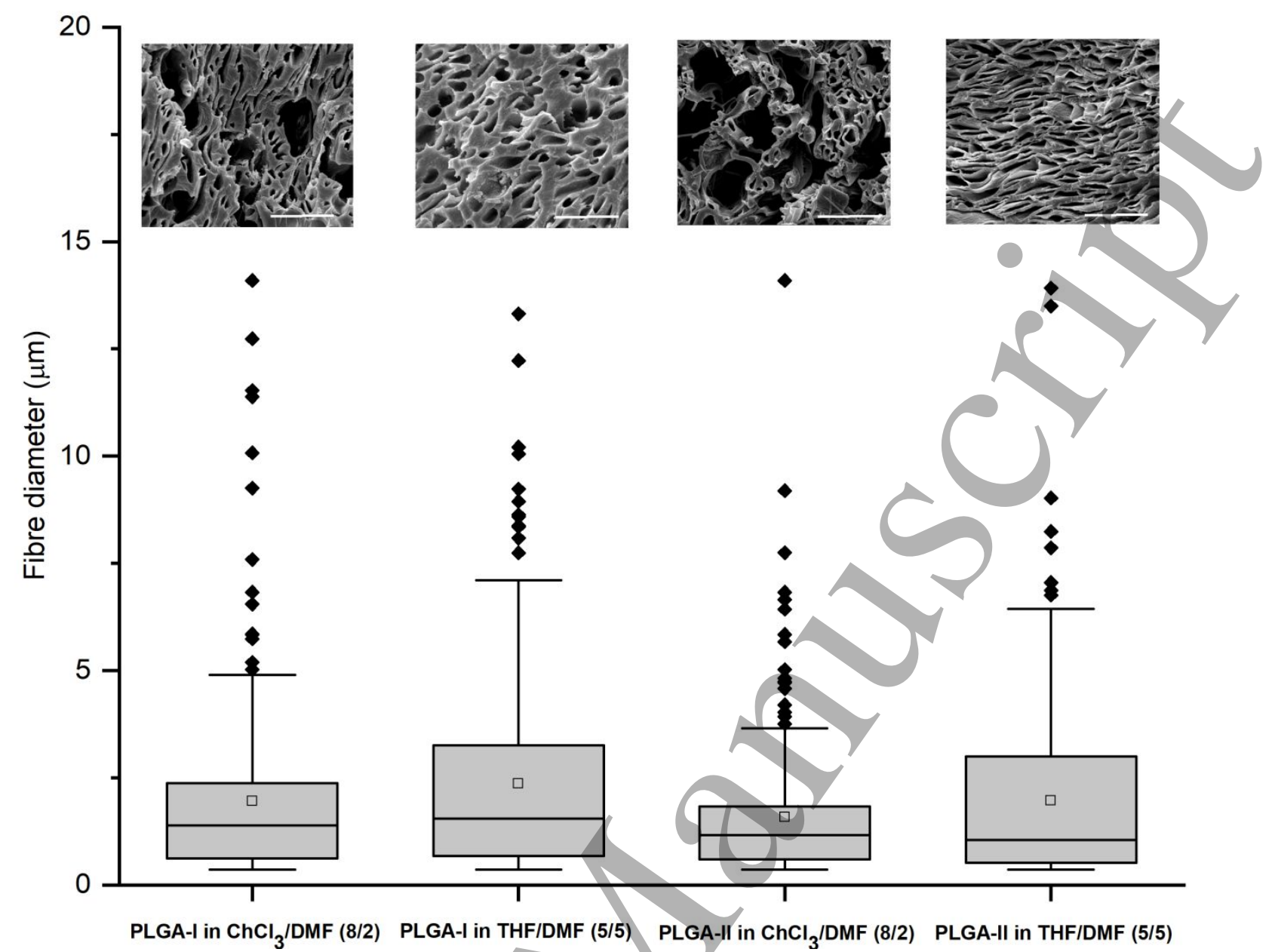

Figure 7. Boxplots of pore size of co-electrospun hollow PLGA fibres under various core and shell solution combinations. Scale bars in SEM micrographs :20 $\mu \mathrm{m}$.

\subsection{MR imaging of water-filled PCL- $b$-PEG and PLGA fibre phantoms}

The dMRI signal is sensitive to the diffusion of water molecules in the phantoms and reflects the extent to which the phantom microstructure restricts or hinders molecular motion. Fig. 8 shows the MD and FA maps of two fibre phantoms and one free water phantom in a $5 \mathrm{~mm}$ glass tube with corresponding colour bars. It can be clearly seen from the MD map (Fig. 8a) that the diffusion coefficient in the phantoms is lower than free water, indicating water diffusion in the phantoms is restricted and/or hindered. The FA map (Fig. 8b) provides evidence of anisotropy in both the PCL- $b$-PEG and PLGA fibre phantoms, which is expected given the uniaxially aligned fibre strips (Fig. 5a-c and Fig. 6c-d). 

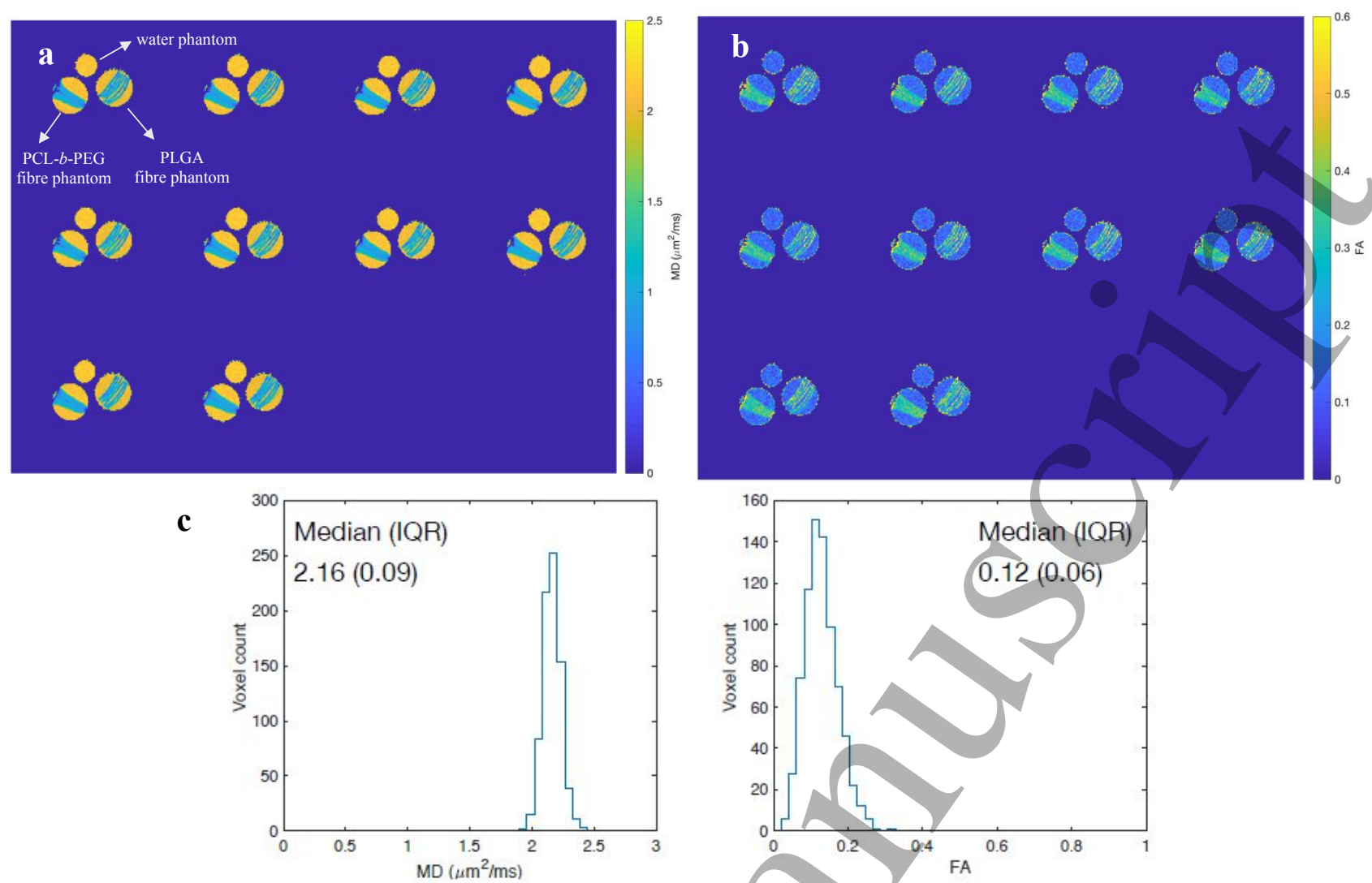

d
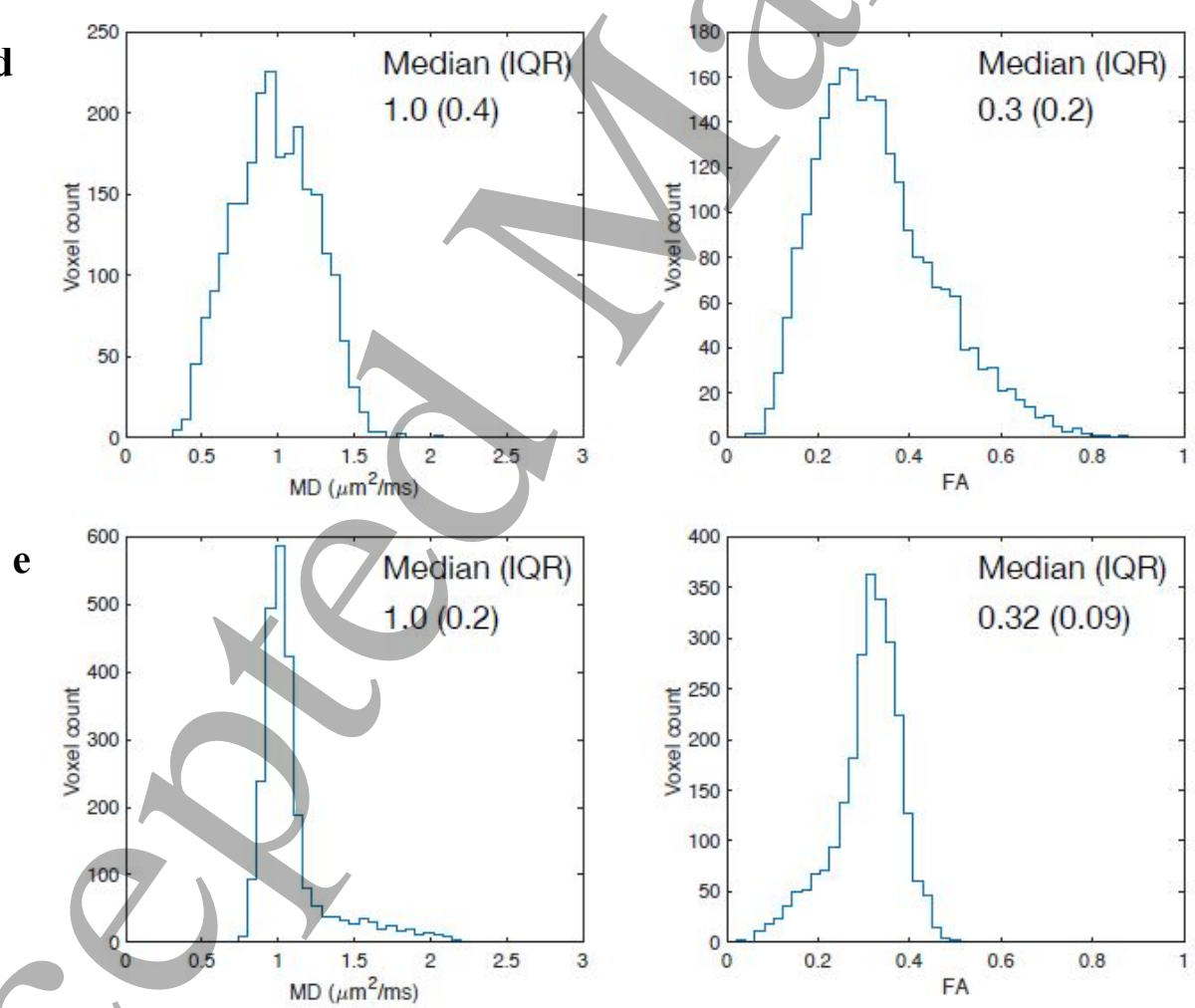

Figure 8. (a-b) MD and FA maps from 10 contiguous slices through three phantom samples: top tube - distilled water phantom as control; bottom left tube - PCL- $b$-PEG1000 fibre phantom (set 1 , Table 2); Bottom right tube - PLGA fibre phantom (set 5, Table 2); MD and FA histograms of (c) Water phantom; (d) PLGA fibre phantom. and (e) PCL- $b$-PEG1000 fibre phantom 
Fig. 8c-e shows the MD and FA values extracted from ROIs in each phantom. It is clear that the free water phantom has narrower MD and FA distributions (Fig. 8c) than both hollow fibre phantoms due to its homogeneity. Free water has an MD value of $2.16 \mu \mathrm{m}^{2} / \mathrm{ms}$, in close agreement with literature values [37] and an FA value of 0.12, which is expected to be close to zero due to isotropic diffusion in the water-filled tube. The discrepancy in MD and non-zero FA between two free water phantoms could be attributed to the low number of diffusion directions, only 6. FA is known to be overestimated due to noise, making isotropic diffusion appear to have a low level of anisotropy [38], which explains the non-zero FA in the water-filled tube. The PCL- $b$-PEG fibre phantom has narrower distributions of MD and FA (Fig. 7e) than those of the PLGA fibre phantom (Fig. 7d), though the corresponding median values of MD and FA of these two fibre phantoms are very similar. As shown in the MD andFA maps (Fig. 7a-b), in the PLGA fibre phantom sample there are six layers of strips in which gaps between fibre strips are present; in the PCL- $b$-PEG fibre strips there are only two fibre layers without obvious gaps present. The inhomogeneous structure in the PLGA fibre phantom can result in the partial volume effects where both fibres and free water contribute to the signal in voxels at the interface, and thus affect dMRI measurements. This is consistent with previous observations, where decreased values of FA were observed in partial voluming of free water [39] or free cyclohexane [40] filled fibre phantoms. The partial volume could contribute to the relatively wider distributions of MD and FA values of the PLGA fibre phantom. This effect could be minimized by tighter packing of the fibre strips, using thicker fibre strips, or increasing the image resolution. In addition, it should be noted that the values of MD and FA vary with diffusion time [37]. The diffusion time used here was much shorter than that typically used on a clinical scanner, which makes it difficult to compare the values of MD and FA with those from typical clinical MR scans. It is expected that with longer diffusion times, MD of these phantoms will decrease, and FA will increase.

It can be envisaged that that MD and FA values of these copolymer fibre phantoms are sensitive to pore sizes and fibre orientation, as demonstrated in previous PCL fibre phantoms [29, 41, 42], but here the primary discussion only focused on two copolymers' feasibility as MRI phantom material. In addition, PCL fibre phantoms have high reproducibility [29, 42]. We expect this reproducibility could also be achieved with the current co-electrospun phantom fibres. Future research will serve to reveal the relationship between MRI measurements with two copolymer fibres' microstructures.

\section{Conclusion}

In this feasibility study, hollow PCL- $b$-PEG and PLGA microfibres were successfully generated via co-electrospinning and used to construct water-filled axon-mimicking phantoms in which water diffusion was restricted/hindered and anisotropic as shown by diffusion MRI. The polymer molecular weight, core solvents and polymer concentration all had considerable effects on the ease of processing and the morphology of the resultant electrospun PCL- $b$-PEG and PLGA fibres. The optimized PCL$b$-PEG and PLGA solutions permitted the one-step formation of axon-mimicking hollow microfibres in a co-electrospinning process at ambient conditions. Both the solvents and polymer molecular weight can dramatically influence the pore size distributions of hollow PLGA fibre strips. These findings have demonstrated that co-electrospinning has competitive advantages over other two phantom manufacturing techniques, i.e. fusion deposition modelling (FDM) 3D printing and melt-spinning. Two water-filled prototype dMRI phantoms constructed from PCL- $b$-PEG and PLGA hollow fibres have clearly shown anisotropic diffusion properties. The phantoms could be first employed to validate MD/FA from DTI and then extended to validate pore size estimated from microstructural models.

\section{Acknowledgements}

This research was supported by NIHR UCLH Biomedical Research Centre (BRC) grant. GJM Parker has a shareholding and part time appointment and directorship at Bioxydyn Ltd, which provides 
quantitative MRI services. He is also a director and shareholder of Queen Square Analytics Ltd, which provides quantitative MRI services.

\section{References}

1. Liewald, D., et al., Distribution of axon diameters in cortical white matter: an electron-microscopic study on three human brains and a macaque. Biological Cybernetics, 2014. 108(5): p. 541-557.

2. Göktepe, S., et al., A multiscale model for eccentric and concentric cardiac growth through sarcomerogenesis. Journal of Theoretical Biology, 2010. 265(3): p. 433-442.

3. Alexander, D.C., et al., Imaging brain microstructure with diffusion MRI: practicality and applications. NMR in Biomedicine, 2019. 32(4): p. e3841.

4. Fieremans, E. and H.-H. Lee, Physical and numerical phantoms for the validation of brain microstructural MRI: A cookbook. Neurolmage, 2018. 182: p. 39-61.

5. Guise, C., et al., Hollow Polypropylene Yarns as a Biomimetic Brain Phantom for the Validation of High-Definition Fiber Tractography Imaging. ACS Applied Materials \& Interfaces, 2016. 8(44): p. 29960-29967.

6. Fan, Q., et al., Validation of diffusion MRI estimates of compartment size and volume fraction in a biomimetic brain phantom using a human MRI scanner with $300 \mathrm{mT} / \mathrm{m}$ maximum gradient strength. Neurolmage, 2018. 182: p. 469-478.

7. Abu-Sardanah, S., et al., Design and evaluation of a diffusion MRI fibre phantom using 3D printing. SPIE Medical Imaging. Vol. 10573. 2018: SPIE.

8. Provenzale, J.M., et al., Analysis of variability of fractional anisotropy values at $3 T$ using a novel diffusion tensor imaging phantom. The Neuroradiology Journal, 2018. 31(6): p. 581-586.

9. Mushtaha, F.N., et al., Microstructural characterization and validation of a 3D printed phantom for diffusion MRI. bioRxiv, 2020: p. 2020.07.02.185397.

10. Sudhir Pathak, W.S., Anthony Zuccolotto, Susie Huang, Qiuyun Fan, Thomas Witzel, Lawrence Wald, Els Fieremans, Michal E. Komlosh, Dan Benjamini, Alexandru V Avram, and Peter J. Basser. Diffusion ground truth quantification of axon scale phantom: Limits of diffusion MRI on $7 T, 3 T$ and Connectome 1.0. in Proc. Int. Soc. Mag. Reson. Med. 28 (2020), 0737. 2020.

11. Walter Schneider, S.P., Yijen Wu, David Busch, and John Dzikiy. Taxon anisotropic phantom delivering human scale parametrically controlled diffusion compartments to advance cross laboratory research and calibration. in Proc. Intl. Soc. Mag. Reson. Med. 27 (2019), 3634. 2019.

12. Zhou, F.-L., et al., Coaxially Electrospun Axon-Mimicking Fibers for Diffusion Magnetic Resonance Imaging. ACS Applied Materials \& Interfaces, 2012. 4(11): p. 6311-6316.

13. Zhou, F.-L., et al., Co-electrospun Brain Mimetic Hollow Microfibres for Diffusion Magnetic Resonance Imaging, in Electrospinning for High Performance Sensors, A. Macagnano, E. Zampetti, and E. Kny, Editors. 2015, Springer International Publishing: Cham. p. 289-304.

14. Dror, Y., et al., One-Step Production of Polymeric Microtubes by Co-electrospinning. Small, 2007. 3(6): p. 1064-1073.

15. Zhang, Z., et al., Electro-Hydrodynamic Direct-Writing Technology toward Patterned Ultra-Thin Fibers: Advances, Materials and Applications. Nano Today, 2020. 35: p. 100942.

16. Zhou, F.-L., et al., Production and cross-sectional characterization of aligned co-electrospun hollow microfibrous bulk assemblies. Materials Characterization, 2015. 109: p. 25-35.

17. Liashenko, I., J. Rosell-Llompart, and A. Cabot, Ultrafast 3D printing with submicrometer features using electrostatic jet deflection. Nature Communications, 2020. 11(1): p. 753.

18. Zhou, F.-L., et al., Axon mimicking hydrophilic hollow polycaprolactone microfibres for diffusion magnetic resonance imaging. Materials \& Design, 2018. 137(Supplement C): p. 394-403.

19. Malikmammadov, E., et al., PCL and PCL-based materials in biomedical applications. Journal of Biomaterials Science, Polymer Edition, 2018. 29(7-9): p. 863-893.

20. Elmowafy, E.M., M. Tiboni, and M.E. Soliman, Biocompatibility, biodegradation and biomedical applications of poly(lactic acid)/poly(lactic-co-glycolic acid) micro and nanoparticles. Journal of Pharmaceutical Investigation, 2019. 49(4): p. 347-380. 
21. Knop, K., et al., Poly(ethylene glycol) in Drug Delivery: Pros and Cons as Well as Potential Alternatives. Angewandte Chemie International Edition, 2010. 49(36): p. 6288-6308.

22. Allen, C., et al., Polycaprolactone-b-poly(ethylene oxide) copolymer micelles as a delivery vehicle for dihydrotestosterone. Journal of Controlled Release, 2000. 63(3): p. 275-286.

23. Meier, M.A.R., et al., PEO-b-PCL Block Copolymers: Synthesis, Detailed Characterization, and Selected Micellar Drug Encapsulation Behavior. Macromolecular Rapid Communications, 2005. 26(24): p. 1918-1924.

24. Zhu, X., et al., Modifying the Hydrophilic-Hydrophobic Interface of PEG-b-PCL To Increase Micelle Stability: Preparation of PEG-b-PBO-b-PCL Triblock Copolymers, Micelle Formation, and Hydrolysis Kinetics. Macromolecules, 2012. 45(2): p. 660-665.

25. Wang, H., et al., A facile strategy for fabricating PCL/PEG block copolymer with excellent enzymatic degradation. Polymer Degradation and Stability, 2017. 140: p. 64-73.

26. Reddy, C.S., et al., Fabrication of thermoset polymer nanofibers by co-electrospinning of uniform core-shell structures. Journal of Materials Chemistry, 2009. 19(39): p. 7198-7201.

27. Liu, X., et al., Electrospinnability of Poly Lactic-co-glycolic Acid (PLGA): the Role of Solvent Type and Solvent Composition. Pharmaceutical Research, 2017. 34(4): p. 738-749.

28. McHugh, D.J., et al., A biomimetic tumor tissue phantom for validating diffusion-weighted MRI measurements. Magnetic Resonance in Medicine, 2017: p. n/a-n/a.

29. Hubbard, P.L., et al., Biomimetic phantom for the validation of diffusion magnetic resonance imaging. Magnetic Resonance in Medicine, 2015. 73(1): p. 299-305.

30. Sitt, A., et al., Microscale Rockets and Picoliter Containers Engineered from Electrospun Polymeric Microtubes. Small, 2016. 12(11): p. 1432-1439.

31. Lee, G.H., J.-C. Song, and K.-B. Yoon, Controlled wall thickness and porosity of polymeric hollow nanofibers by coaxial electrospinning. Macromolecular Research, 2010. 18(6): p. 571-576.

32. Tiwari, S.K., et al., Optimizing partition-controlled drug release from electrospun core-shell fibers. International Journal of Pharmaceutics, 2010. 392(1-2): p. 209-217.

33. Moghe, A.K. and B.S. Gupta, Co-axial Electrospinning for Nanofiber Structures: Preparation and Applications. Polymer Reviews, 2008. 48(2): p. 353-377.

34. Halaui, R., et al., Polymeric microtubes for water filtration by co-axial electrospinning technique. Polymers for Advanced Technologies, 2017. 28(5): p. 570-582.

35. Dziemidowicz, K., et al., Electrospinning for healthcare: recent advancements. Journal of Materials Chemistry B, 2021.

36. Chou, S.-F. and K.A. Woodrow, Relationships between mechanical properties and drug release from electrospun fibers of PCL and PLGA blends. Journal of the mechanical behavior of biomedical materials, 2017. 65: p. 724-733.

37. Clark, C.A., M. Hedehus, and M.E. Moseley, Diffusion time dependence of the apparent diffusion tensor in healthy human brain and white matter disease. Magnetic Resonance in Medicine, 2001. 45(6): p. 1126-1129.

38. Armitage, P.A. and M.E. Bastin, Selecting an appropriate anisotropy index for displaying diffusion tensor imaging data with improved contrast and sensitivity. Magnetic Resonance in Medicine, 2000. 44(1): p. 117-121.

39. Yeh, F.-C., et al., Deterministic Diffusion Fiber Tracking Improved by Quantitative Anisotropy. PLOS ONE, 2013.8(11): p. e80713.

40. Teh, I., et al., Biomimetic phantom for cardiac diffusion MRI. Journal of magnetic resonance imaging : JMRI, 2016. 43(3): p. 594-600.

41. Ye, A.Q., et al., Diffusion tensor MRI phantom exhibits anomalous diffusion. Annual International Conference of the IEEE Engineering in Medicine and Biology Society. IEEE Engineering in Medicine and Biology Society. Annual International Conference, 2014. 2014: p. 746-749.

42. Grech-Sollars, M., et al., Stability and reproducibility of co-electrospun brain-mimicking phantoms for quality assurance of diffusion MRI sequences. Neurolmage, 2018. 181: p. 395-402. 